\title{
A Study on Extinction of RDF (Refuse Derived Fuel) Pile
}

TAKESHI SUZUKI, TAKASHI TSURUDA, YOSHIO OGAWA, and

CHIHONG LIAO

National Research Institute of Fire and Disaster

3-14-1, Nakahara-cho

Mitaka-shi, Tokyo 181-8633, JAPAN

\begin{abstract}
Tests were conducted with the objectives of observing and recording the characteristics of fire growth and extinction of RDF fire, and to establish a tentative basis for the development of safety and fire control requirements. An RDF sample used was a pellet type made from municipal solid waste. A pile of RDF pellets was ignited and burned for predetermined burn time. By applying water mist, flame over the pile was extinguished. When burn time was longer than $30 \mathrm{~min}$, hot area remained on the surface after extinguishing flame. The hot area expanded with time. Smoke was emitted from the hot area. After the pile was cut open for inspection, hot area was found inside the pile. RDF pellets are aggregated by heating since shredded plastics contained in them melt and work as adhesive. By applying water, aggregated pellets are cooled to form a layer which prevents water from soaking inside. RDF pellets remain hot under the layer. If air is supplied to hot RDF pellets under the layer, oxidation continues and heat and smoke are emitted.
\end{abstract}

KEYWORDS: RDF, smouldering, water mist, extinction

\section{NOMENCLATURE}

$a$ distance from the base to the front of area of dark brown or blackened area $(\mathrm{cm})$

$b$ distance from the base to the surface $(\mathrm{cm})$

$d \quad$ Depth of charred area $(\mathrm{cm})=b-a$

$t$ time after ignition (min)

\author{
Greek \\ $\alpha \quad$ thermal diffusivity $\left(\mathrm{m}^{2} / \mathrm{s}\right)$ \\ $\tau \quad$ burn time (min)
}

\section{INTRODUCTION}

With the depletion of space for landfilling of municipal solid waste (MSW). More MSW is treated by incineration other than by direct landfilling, and its thermal energy is recovered. A technology has been introduced into Japan to pre-treat solid waste by crushing, drying, screening and molding it into a densified refuse derived fuel (RDF). RDF can be produced in small or medium sized municipalities, transported to combustion site, stored, and then burnt in large-scale boilers for generating electricity. Most of Japanese RDF are densified type, which are manufactured by adding calcium compounds and are classified as RDF-5 by ASTM standard [1]. Technical reference to RDF is defined in Japanese Industrial Standard [2].

Five areas are selected for practical operation of power plants of RDF from year 2003. They are in Ibaragi Prefecture, Mie Prefecture, Ishikawa Prefecture, Hiroshima Prefecture, and Fukuoka Prefecture. The incinerators used in those power plants were 
operated for reducing Dioxin generation and maximizing energy conversion. To achieve the low Dioxin emission and maximizing energy conversion, the capacity of the incinerator was selected to be 200 ton/day in Mie Prefecture. A large amount of RDF was stored in a silo in the incinerator plant in Mie Prefecture. Just after loading RDF in the silo, unexpected heating was detected in December 2002 [3-5]. After the unexpected heating, RDF was stored in a conventional warehouse temporarily. Fire of RDF occurred in the conventional warehouse in June 2003. It was extinguished by the local fire department. The extinguished RDF was loaded in the silo for incineration. In mid summer in 2003, the operator of the incinerator of RDF asked the local fire department to cool down RDF heated in the silo after experiencing an explosion that resulted four injured workers. Another explosion killed two firefighters and injured one worker. It had been shown that the content of the silo would heat up and ignite by itself. If people expect the extinction means that there is no other fire in the silo, all of the content of the silo need to be removed. To remove all of the content of the silo, the damage control task force cooled the silo and unloaded the content. In September 2003 the silo was emptied and the fire was extinguished.

RDF is used for boiler fuel. Therefore combustion characteristics in boilers have been investigated. Also characteristics of thermal degradation of RDF have been investigated by means of thermal gravimetric analysis (TGA) and differential thermal analysis (DTA). Information obtained through those investigations was summarized in review papers [69]. It seemed that information needed for constructing power plants was obtained. However investigations on safe handling and safe storage of RDF were very few. When fire occurred in a silo storing RDF in Mie Prefecture, information needed for fire-fighting activity of RDF was insufficient. Knowledge on ignition, fire development, and extinction of RDF is indispensable for fire fighting. Gao et al. studied spontaneous ignition of RDF $[10,11]$. Critical ignition temperature based on Frank-Kamenetskii theory was calculated. Yashima studied fire spread in piled RDF [12]. RDF was piled in a cylinder made from heat insulator and was heated from below. Analyzing vertical variations in temperatures in the pile, he obtained upward fire spread rate ranging from $0.24 \mathrm{~mm} / \mathrm{min}$ to $1.8 \mathrm{~mm} / \mathrm{min}$. Yokkaichi Fire Department conducted experiments of extinction of burning RDF [13]. RDF (3 kg) was placed in a can (30 cm in diameter and $36 \mathrm{~cm}$ in height). Holes were opened near the bottom for air supply. The can was heated from below using a gas flame and RDF burned. Some extinguishing agents (water, foam, water containing surfactant, powder, and carbon dioxide) were applied. Flame was extinguished under tested conditions. However, in some cases, smouldering or reignition were observed.

In the present study, tests were conducted with the objectives of observing and recording the characteristics on fire growth and extinction of RDF fire, and to establish a tentative basis for the development of safety and fire control requirements. RDF samples were piled on a metal tray and burned. Reaction to water application was observed by temperature measurement using thermocouples and thermal image cameras. Fires in large piles tend to burrow down into the pile, making them difficult to extinguish [14]. Burn time of flaming combustion can affect heat transferred into the pile and reaction to water application. Effects of burn time of flaming combustion were also investigated. 
TEST PREPARATION

\section{Characteristics of RDF Used in Experiments}

An RDF sample used in the experiments was a pellet type made from municipal solid waste in Mie Prefecture. Table 1 shows information of RDF pellets in Mie Prefecture.

Table 1. Information of RDF.

\begin{tabular}{|c|c|}
\hline Ingredients [15] & Properties [15] \\
\hline $\begin{array}{ll}\text { Paper, cloth } & 57.1 \% \\
\text { Plastics } & 17.3 \% \\
\text { Wood, bamboo, straw } & 4.0 \% \\
\text { Kitchen waste } & 18.6 \% \\
\text { Incombustibles } & 1.4 \% \\
\text { Others } & 1.8 \%\end{array}$ & $\begin{array}{l}\text { Higher heat of combustion(MJ/kg) } \\
\quad: 18.3-20.4,19.4 \text { (average) } \\
\text { Lower heat of combustion(MJ/kg) } \\
\quad: 16.7-17.8,17.6 \text { (average) } \\
\text { Bulk density }\left(\mathrm{g} / \mathrm{cm}^{3}\right) \\
\quad: 0.56-0.65,0.62 \text { (average) } \\
\text { Diameter(mm): } 14.8-29.0,18.0 \text { (average) } \\
\text { Length(mm):23.3 - 54.0, 36.0(average) }\end{array}$ \\
\hline Contents [15] & Appearance \\
\hline $\begin{array}{l}\text { chlorine: } 0.7-1.1 \%, 0.88 \% \text { (average) } \\
\text { calcium: } 1.4-6.2 \%, 2.77 \% \text { (average) } \\
\text { Ash: } 10.6 \text { - } 12.7 \%, 11.5 \% \text { (average) } \\
\text { water: } 1.8-4.7 \%, 3.4 \% \text { (average) }\end{array}$ & 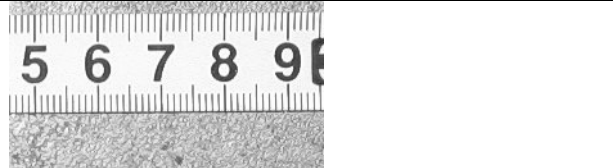 \\
\hline \multicolumn{2}{|c|}{ Thermal degradation characteristics (TG and DTA analysis) [3] } \\
\hline $\begin{array}{l}\text { in nitrogen, heating rate: } 10^{\circ} \mathrm{C} / \mathrm{min} \\
\text { mass loss }(\mathrm{wt} \%) \quad \text { temperature }\left({ }^{\circ} \mathrm{C}\right)\end{array}$ & $\begin{array}{l}\text { In air, heating rate: } 10{ }^{\circ} \mathrm{C} / \mathrm{min} \\
\text { mass loss [wt } \%] \quad \text { temperature }\left({ }^{\circ} \mathrm{C}\right)\end{array}$ \\
\hline $\begin{array}{ll}2.4 & \mathrm{RT}(\text { room temperature) } \\
& \text { to } 150\end{array}$ & $\begin{array}{ll}2.8 & \text { RT to } 150 \\
55.4 & \text { RT to } 400\end{array}$ \\
\hline RT to 400 & RT to 550 \\
\hline $\mathrm{RT}$ to 550 & $\mathrm{RT}$ to 800 \\
\hline $\mathrm{RT}$ to 800 & $\mathrm{RT}$ to 1000 \\
\hline $\begin{array}{l}76.3 \quad \mathrm{RT} \text { to } 1000 \\
\text { peak temperature by DTG }\left[{ }^{\circ} \mathrm{C}\right] \\
: 78,342,485,670 \\
\text { initiation temperature of mass loss } \\
: 284^{\circ} \mathrm{C}\end{array}$ & $\begin{array}{l}\text { peak temperature by DTG }\left[{ }^{\circ} \mathrm{C}\right] \\
: 78,302,419,667 \\
\text { initiation temperature of mass loss }: 267^{\circ} \mathrm{C} \\
\text { initiation temperature of heat release by } \\
\text { DTA : } 236^{\circ} \mathrm{C}\end{array}$ \\
\hline \multicolumn{2}{|l|}{ Thermal properties [3] } \\
\hline \multicolumn{2}{|c|}{$\begin{array}{l}\text { Specific heat }(\mathrm{J} / \mathrm{kg} \cdot \mathrm{K}): 1410 \\
\text { Thermal diffusivity }\left(10^{-7} \mathrm{~m}^{2} / \mathrm{s}\right): 1.11 \\
\text { Thermal conductivity }(\mathrm{W} / \mathrm{m} \cdot \mathrm{K}): 0.149 \text { at } 25^{\circ} \mathrm{C}, 947 \mathrm{~kg} / \mathrm{m}^{3}\end{array}$} \\
\hline
\end{tabular}

\section{Setup of RDF pile}

A pile of RDF (height: $15 \mathrm{~cm}$, base: $75 \mathrm{~cm}$ x $75 \mathrm{~cm}$, weight: $20 \mathrm{~kg}$ ) was made on a metal tray (inner dimensions: $90 \mathrm{~cm}$ x $90 \mathrm{~cm}$ x $10 \mathrm{~cm}$, thickness of metal: $1.5 \mathrm{~mm}$ ) as shown in Fig. 1. It was not easy to achieve sustained combustion of RDF. When attached to a 
flame, RDF pellets gasifies. If flame is removed, combustion is not sustained. The method used in this study was least time-consuming and easiest way to ignite RDF among methods tried. One minute before ignition heptane of $3 \mathrm{dm}^{3}$ was poured over the pile surface. A torch was prepared consisting of waste rags soaked with heptane wrapped around and wire-bound to a $1 \mathrm{~m}$ metal rod. The burning torch was applied to the surface of the pile and the pile was ignited immediately. After heptane burned out, RDF pellets continued flaming combustion. When heptane with free surface burns in the metal tray used in the experiments, it burns out approximately within $90 \mathrm{~s}$.

\section{Test Site}

The tests were conducted in a room shown in Fig. 2. The dimensions of the room are $25 \mathrm{~m}$ (w) x $25 \mathrm{~m}$ (d) x $22 \mathrm{~m}$ (h). Metal tray was placed near the centre of floor. The room has an opening of $6.5 \mathrm{~m} \mathrm{(w)} \mathrm{x} 6.5 \mathrm{~m}(\mathrm{~h})$ for an air intake. The room has a smoke exhaust system. The maximum exhaust flow rate is $90,000 \mathrm{~m}^{3} / \mathrm{hr}$. The system was kept activated during the test.

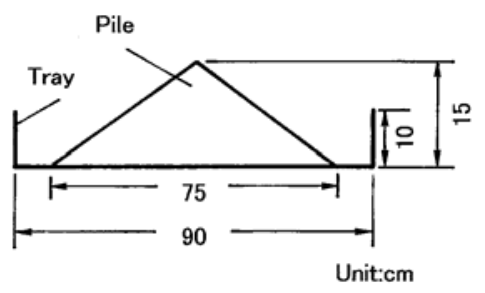

Fig. 1. Outline of pile (Not to scale).

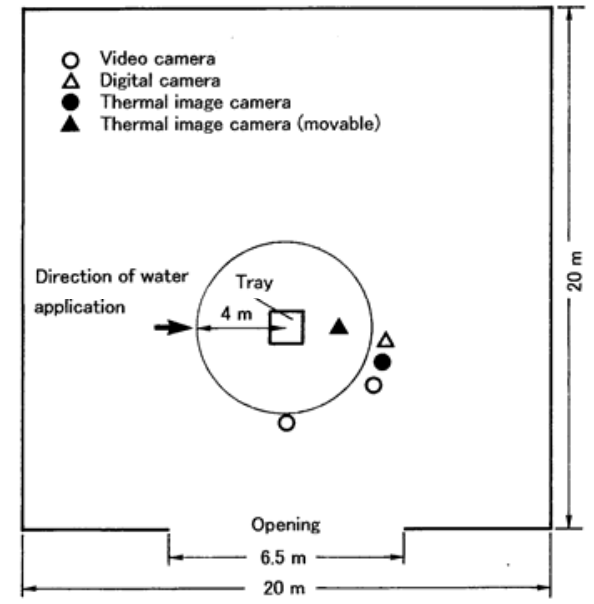

Fig.2. Layout in the test room (Not to scale).

\section{Instrumentation}

\section{Temperature measurements}

Temperatures inside the pile and air temperature above the pile surface were measured. The location of thermocouples is shown in Table 2 and Fig. 3. In Tests 1 and 2, three thermocouples (chromel/alumel in $1.6 \mathrm{~mm}$ diameter sheath) were placed along the centre axis of the pile, $5 \mathrm{~cm}, 12 \mathrm{~cm}$, and $17 \mathrm{~cm}$ above the base of the pile. Thermocouples at $5 \mathrm{~cm}$ and $12 \mathrm{~cm}$ above the base were buried in the pile. Thermocouple at $17 \mathrm{~cm}$ above the base was used to measure gas temperature. In Test 2, a thermocouple was attached on the pile surface after applying water. In Test 3, six thermocouples were placed along the centre axis of the pile, $5 \mathrm{~cm}, 12 \mathrm{~cm}, 13 \mathrm{~cm}, 14 \mathrm{~cm}, 15 \mathrm{~cm}$, and $17 \mathrm{~cm}$ above the base. This arrangement enabled measurement of the vertical distribution of temperature in the pile. Three thermocouples were attached near the pile surface after applying water.

Table 2. Experimental condition. 


\begin{tabular}{|l|l|l|l|}
\hline \multirow{2}{*}{ Burn time } & \multicolumn{2}{|c|}{ Thermocouples } \\
\cline { 3 - 4 } & & Centre axis & Hot area \\
\hline Test 1 & $10 \mathrm{~min}$ & $5,12,17 \mathrm{~cm}$ above base & \\
\hline Test 2 & $30 \mathrm{~min}$ & $5,12,17 \mathrm{~cm}$ above base & Surface \\
\hline Test 3 & $60 \mathrm{~min}$ & $\begin{array}{l}5,12,13,14,15,17 \mathrm{~cm} \\
\text { above base }\end{array}$ & $\begin{array}{l}\text { surface, } 1 \mathrm{~cm} \text { beneath surface, } 2 \\
\text { cm beneath surface }\end{array}$ \\
\hline
\end{tabular}
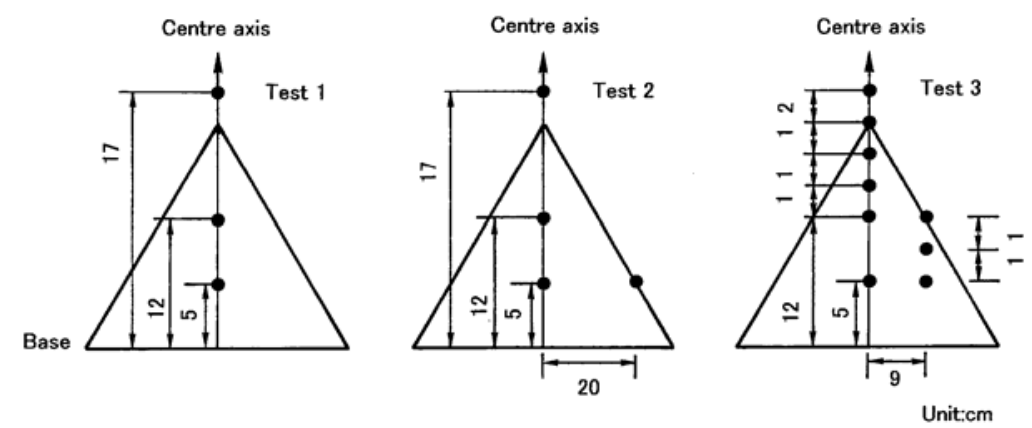

Fig. 3. Location of thermocouples (Not to scale).

\section{Monitoring by Cameras}

At least two video cameras, two thermal image cameras (NEC SANEI TH7102), and a digital camera were used in every test. Position of these cameras is shown in Fig. 2. Height of the cameras was about $150 \mathrm{~cm}$ from the floor. Position of one of thermal image cameras was not fixed. Emissivity setting of thermal image cameras was unity. Temperature range of thermal image cameras is from 0 to $250^{\circ} \mathrm{C}$.

\section{Extinguishment Operation}

To control and extinguish test fires, a hand line was used in the tests. The line was fitted with a water mist nozzle [16] which is used by Yokohama City Fire Bureau. Water (flow rate: $40 \mathrm{dm}^{3} / \mathrm{min}$ ) and compressed air (flow rate: $1000 \mathrm{dm}^{3} / \mathrm{min}$ ) were mixed and ejected through nozzle. Yokohama City Fire Bureau was in charge of the operation. The operation was done so that water would cause minimal disturbance of pellets and minimum quantity of water would be used. Water application was stopped when operators judged that the burning of pile was stopped by their visual observation.

\section{DESCRIPTION OF TESTS}

Pile was burnt for predetermined burn time. After that, flame was extinguished by applying water mist. Burn time is shown in Table 2. Time for which water was applied is shown in Table 3. 
Table 3. Depth of charred area.

\begin{tabular}{|l|l|l|l|l|}
\hline & Burn time & \multicolumn{1}{|c|}{$\begin{array}{c}\text { Time of water } \\
\text { application }\end{array}$} & $\begin{array}{c}\text { Volume of } \\
\text { water used }\end{array}$ & \multicolumn{1}{c}{$(=\boldsymbol{b}-\boldsymbol{a})$} \\
\hline Test 1 & $10 \mathrm{~min}$ & $\begin{array}{l}12 \mathrm{~s} \text { (first) } \\
11 \mathrm{~s} \text { (second) }\end{array}$ & $\begin{array}{l}20.9 \mathrm{dm}^{3}(\text { total } \\
\text { of first and } \\
\text { second } \\
\text { application) }\end{array}$ & $1.2 \mathrm{~cm}$ \\
\hline Test 2 & $30 \mathrm{~min}$ & $17 \mathrm{~s}$ & $5.7 \mathrm{dm}^{3}$ & $4.1 \mathrm{~cm}$ \\
\hline Test 3 & $60 \mathrm{~min}$ & $12 \mathrm{~s}$ & $3.4 \mathrm{dm}^{3}$ & $5.4 \mathrm{~cm}$ \\
\hline
\end{tabular}

\section{Test 1}

Images taken by a thermal image camera are shown in Fig. 4. Water mist was applied twice. After first water application at $10 \mathrm{~min}$ after ignition, flame was extinguished. But hot area was observed by a thermal image camera on the pile surface. At the hot area, smouldering and emission of smoke continued. After second water application at $14 \mathrm{~min}$ after ignition, smouldering area over the pile surface was cooled. At 15 min after ignition, surface temperature measured by a thermal image camera exceeded $100^{\circ} \mathrm{C}$. Surface temperature dropped with time. At 2 hours after ignition, surface temperature was lowered to the environmental temperature. Observation by a thermal image camera was stopped at 2 hours after ignition. Visual observation was continued until more than three hours passed.

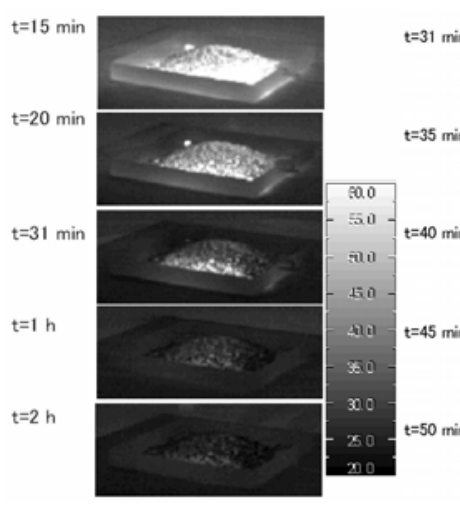

Test 1

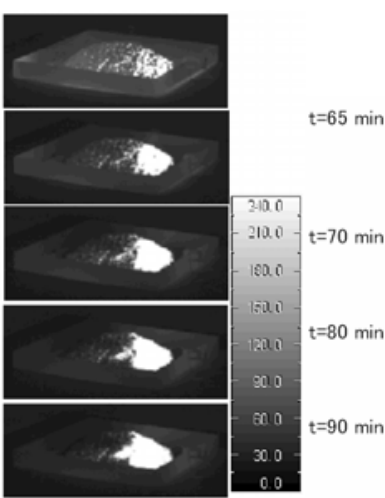

Test 2

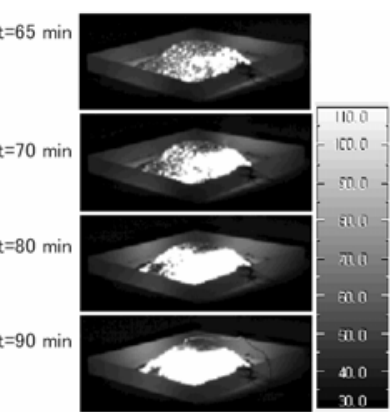

Test 3

Fig. 4. Images taken by a thermal image camera after water application.

Variations in temperatures with time are shown in Fig. 5. Temperature at $17 \mathrm{~cm}$ above the base rose just after ignition and reached more than $700^{\circ} \mathrm{C}$. After first water application, flame was extinguished and temperature at $17 \mathrm{~cm}$ above the base dropped sharply. Temperatures at $5 \mathrm{~cm}$ and $12 \mathrm{~cm}$ above the base rose gradually after ignition. After second water application, temperatures at $5 \mathrm{~cm}$ and $12 \mathrm{~cm}$ above the base dropped gradually. 


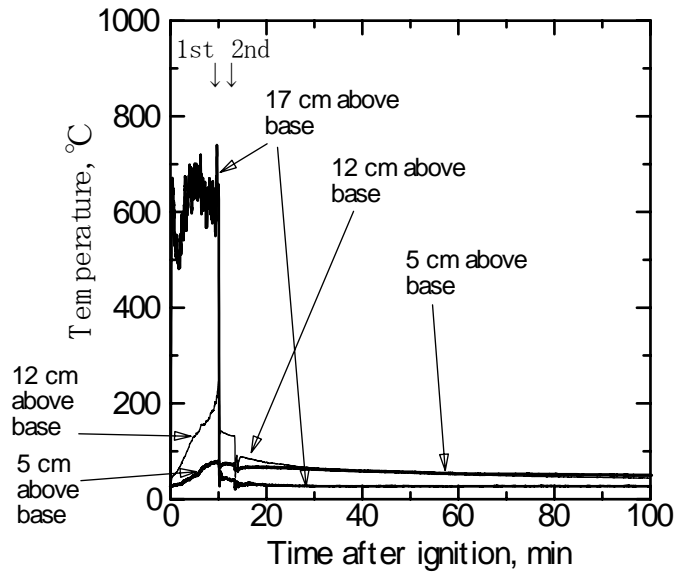

Test 1

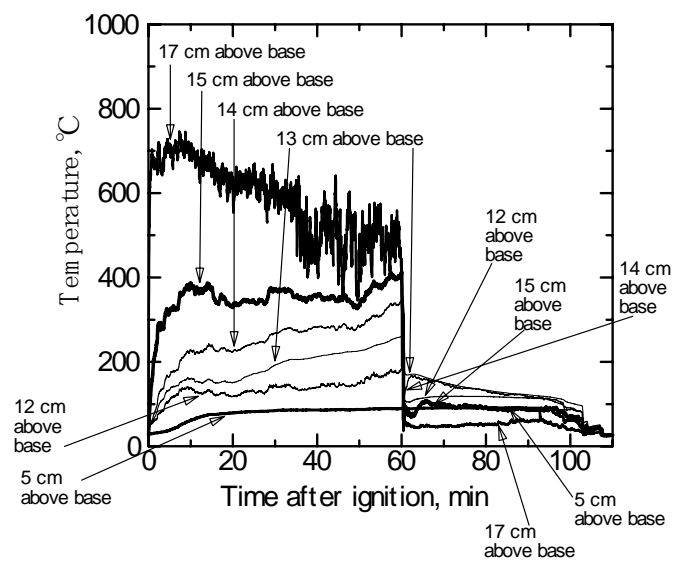

Test 3
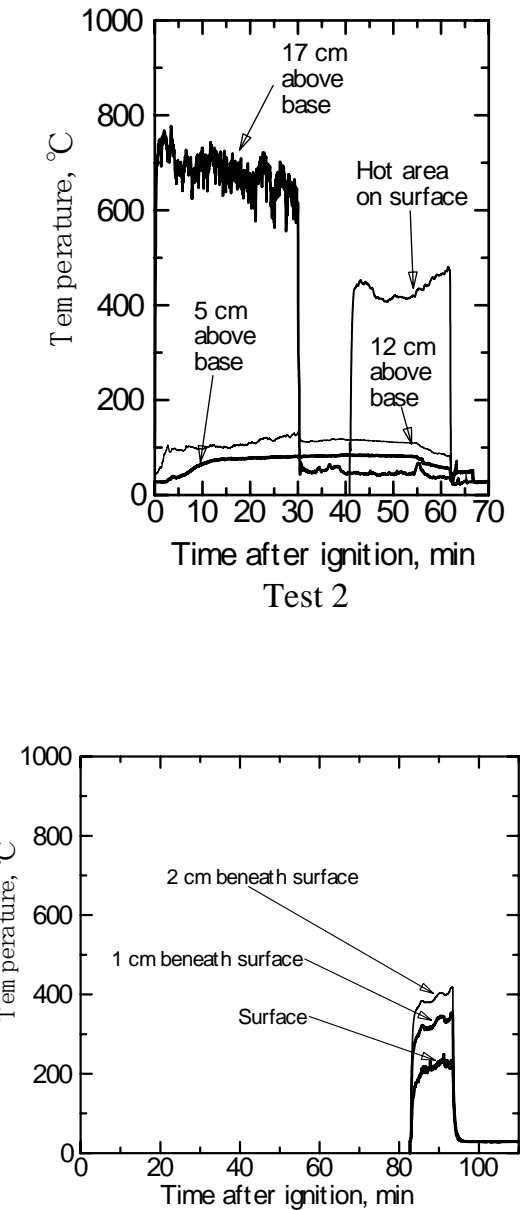

Test 4

Fig. 5. Variation of temperatures with time.

The pile was cut open and cross sectional area was revealed for inspection at $220 \mathrm{~min}$ after ignition. Schematic diagrams of cross sectional area are shown in Fig. 6. Diagrams (a) were drawn from images taken by a thermal image camera. Diagrams (b) were drawn from images taken by a digital camera. Thermal image analysis revealed two distinct regions: (1) Surface, about $30^{\circ} \mathrm{C}$, and (2) Interior of the pile, about $40^{\circ} \mathrm{C}$. Visual observation of cross sectional area revealed three distinct regions: (1) Carbonized surface; (2) Area of dark brown beneath the surface, and (3) Area of no change. In Fig. 6, $a$ denotes distance from the base to the front of area of dark brown and $b$ denotes distance from the base to the surface. 
Temperature beneath the surface is about $40^{\circ} \mathrm{C}$.

It is higher than that of surface by about $10^{\circ} \mathrm{C}$.

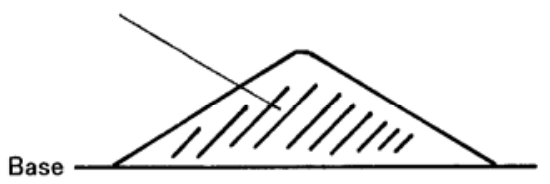

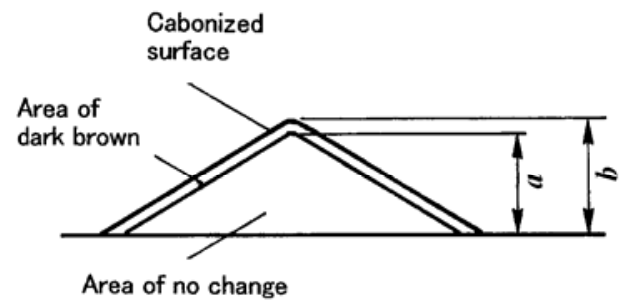

(b)

Test $1(t=220 \mathrm{~min})$

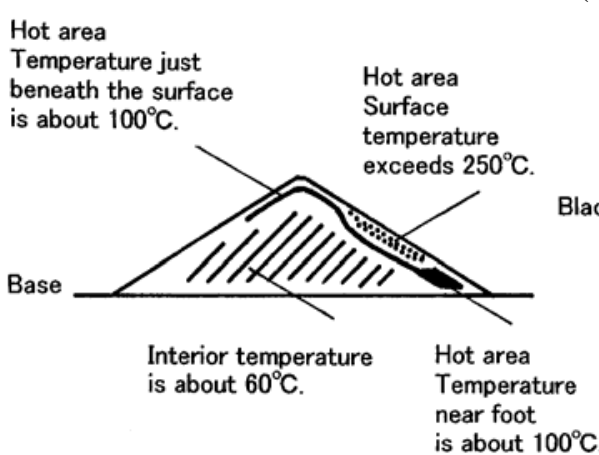

(a)

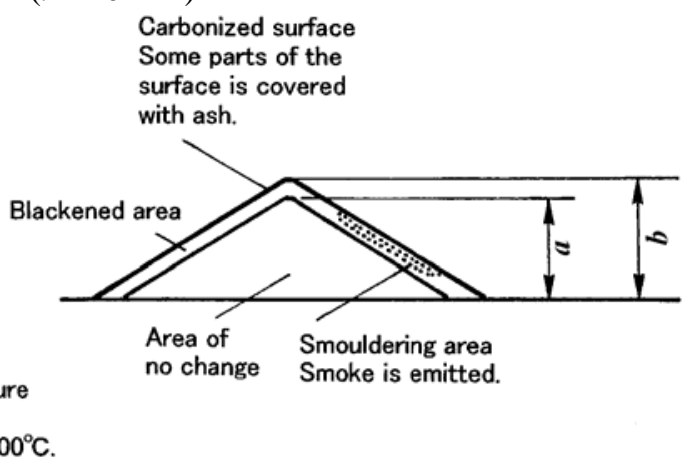

(b)

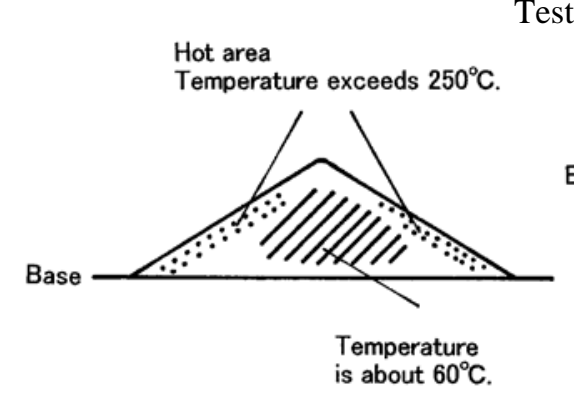

(a)

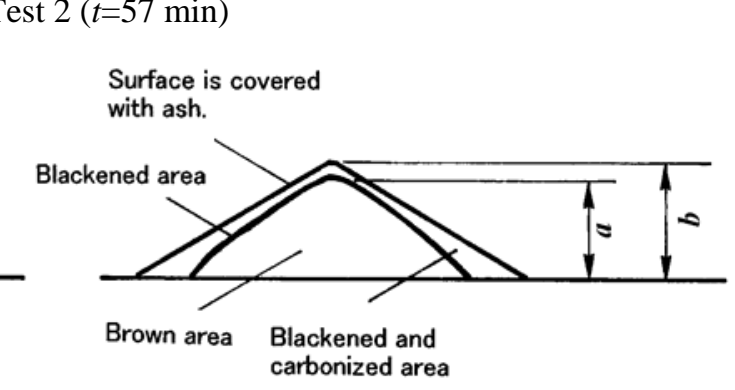

(b)

Test 3 ( $t=97 \mathrm{~min})$

Fig. 6. Schematic diagrams of cross sectional area of pile (not to scale). (a)Drawn from image taken by a thermal image camera.

(b)Drawn from image taken by digital camera.

\section{Test 2}

Images taken by a thermal image camera are shown in Fig. 4. By applying water mist, flame was extinguished at 30 min after ignition. Hot area was found on the surface by a thermal image camera. The temperature in the hottest spots measured by a thermal image camera exceeded $250^{\circ} \mathrm{C}$. Hot area expanded with time. Smoke was seen emitted from the hot area by visual observation. Visual observation and observation by using a thermal image camera were continued for about 30 min after applying water mist. 
Variations in temperatures with time are shown in Fig. 5. Temperature at $5 \mathrm{~cm}$ above the base was unchanged after extinguishing flame by applying water mist. Temperature at $12 \mathrm{~cm}$ above the base dropped slightly when water was applied. At $40 \mathrm{~min}$ a thermocouple was placed on the hot area seen by a thermal image camera. It was $20 \mathrm{~cm}$ away from the centre axis. Temperature of the hot area measured by the thermocouple was more than $400^{\circ} \mathrm{C}$. The distance between the surface and a thermocouple at $5 \mathrm{~cm}$ above the base is about $9 \mathrm{~cm}$. Water was applied on the surface and hot area expanded after that. However, temperature at $9 \mathrm{~cm}$ removed from the surface was unchanged in spite of these changes in phenomena. Limitation of detection by thermocouples due to low thermal diffusivity is suggested.

The pile was divided and cross sectional area was revealed at 55 min after ignition. Schematic diagrams of cross sectional area are shown in Fig. 6. Thermal image analysis revealed four distinct regions: (1) Hot area just beneath the surface, about $100^{\circ} \mathrm{C}$; (2) Interior region, about $60^{\circ} \mathrm{C}$; (3) Hot area near the foot of the pile, about $100^{\circ} \mathrm{C}$, and (4) Hot area on the surface, exceeding $250^{\circ} \mathrm{C}$. Visual observation of cross sectional area revealed four distinct regions: (1) Surface, some part of which was covered with ash; (2) Blackened area beneath the surface where pellets adhered to each other; (3) Area which showed no change, and (4) Smoldering area, from which smoke was emitted. One possible explanation of these diagrams is as follows. RDF pellets were aggregated after heating since shredded plastics contained in the pellets melted and worked as adhesive. By applying water, aggregated pellets were cooled to form a layer which prevented water from soaking inside. Pellets remained hot under the layer. If air was supplied to hot pellets under the layer, oxidation continued and heat and smoke were emitted. In Fig. 6, $a$ denotes distance from the base to the front of blackened area.

RDF pellets can evolve flammable gas when subjected to heat. If temperature of hot area on the surface rose and becomes sufficiently high, the hot surface may be capable of igniting surrounding flammable mixture of thermal degradation products (which contain the volatiles from the pyrolysis reactions).

\section{Test 3}

Images taken by a thermal image camera are shown in Fig. 4. At 60 min after ignition, flame was extinguished by applying water mist. Hot area was found on the surface by a thermal image camera. Temperature at the hottest spot exceeded $250^{\circ} \mathrm{C}$. Hot area expanded with time. Smoke was seen emitted from the hot area by visual observation. Visual observation and observation by using a thermal image camera were continued for about 30 minutes after applying water mist.

Variations in temperatures with time are shown in Fig. 5. Temperature at $5 \mathrm{~cm}$ above base was unchanged after extinguishing flame. Temperature at $12 \mathrm{~cm}$ above the base was stable after water application. Thermocouples were placed on the hot area seen by a thermal image camera at $82 \mathrm{~min}$. They were $9 \mathrm{~cm}$ away from the centre axis. Temperature beneath $2 \mathrm{~cm}$ from the surface was hotter than others. It was suggested that hot area existed inside the pile. Temperatures at $12 \mathrm{~cm}, 13 \mathrm{~cm}$, and $14 \mathrm{~cm}$ above the base were fluctuating before water application. They were like gas temperatures rather than solid temperatures. Also the trends in fluctuations of temperatures at $12 \mathrm{~cm}, 13 \mathrm{~cm}$, and $14 \mathrm{~cm}$ were similar. Fluctuations in temperatures suggested that gas was flowing along the centre axis. 
The pile was divided and cross sectional area was revealed at 94 min after ignition. Schematic diagrams of cross sectional area are shown in Fig. 6. Thermal image analysis revealed two distinct regions: (1) Hot area on the surface and beneath the surface, exceeding $250^{\circ} \mathrm{C}$ and (2) Interior of the pile, about $60^{\circ} \mathrm{C}$. Existence of hot area coincided with the temperature records at $9 \mathrm{~cm}$ from the centre axis. Visual observation of cross sectional area revealed four distinct regions: (1) Surface covered with ash; (2) Blackened and carbonized area beneath the surface; (3) Blackened area, and (4) Brown area.

\section{Spread of Charred Area}

During flaming combustion, heat from flame flowed into interior of RDF layer through the surface. It is considered that colour of pellets changed into black or dark brown by temperature rise. Blackened area or area of dark brown is defined as charred area. Difference between $b$ and $a$ is depth of charred area as shown in Fig. 6. Relation between depth of charred area and burn time is shown in Table 3 and Fig. 7. Diameter of pellets is about $1.5 \mathrm{~cm}$. Error in reading the depth was considered to be equal to pellet diameter. The straight line drawn is defined as a constant spread rate of charred area. The obtained spread rate of charred area is $0.1 \mathrm{~cm} / \mathrm{min}$. Spread rate of charred area obtained in the present study and upward fire spread rate in piled RDF obtained by Yashima [12] is of same order. Assuming colour of pellets changes only by heat penetrating from the surface and neglecting radiative heat transfer within the pile, approximate relation is given [11] as

$d=(\alpha \cdot \tau)^{0.5}$

Where $d(=b-a)$ is depth of charred area, $\alpha$ is thermal diffusivity shown in Table $1, \tau$ is burn time.

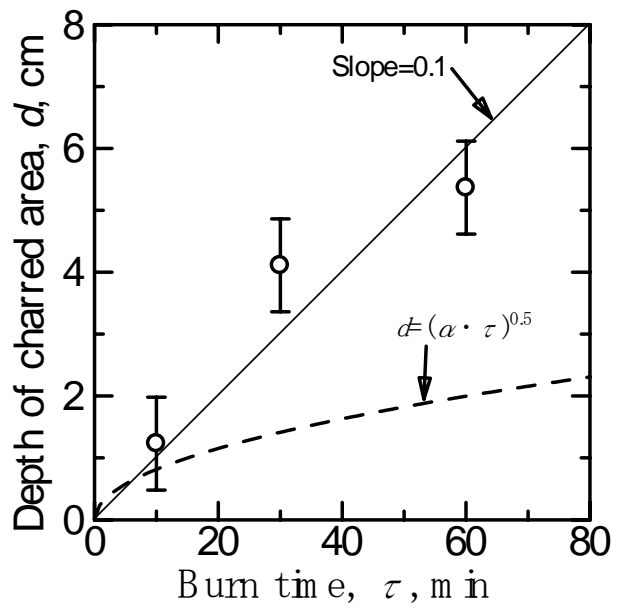

Fig. 7. Relation between burn time and depth of charred area.

Equation 1 is drawn in dashed line in Fig. 7. The line expressing Eq. 1 is below the straight line. One possible explanation is that more heat was conveyed to deeper section and chemical reaction zone moved downward. It is suggested that oxygen was soaked into the charred area and heat was generated in the charred area due to oxidation. Sampling and analysis of gas inside the pile to detect oxidation was not done. 
The thermal diffusivity shown in Table 1 was measured below $100^{\circ} \mathrm{C}$ using unburned RDF pellets which were ground into powder form. The overall thermal diffusivity in the actual burning pile may be different from the thermal diffusivity shown in Table 1 . It may be the cause of the discrepancy between the two lines in Fig. 7.

\section{CONCLUSIONS}

Tests were conducted with the objectives of observing and recording the characteristics of fire growth and extinction of RDF fire, and to establish a tentative basis for the development of safety and fire control requirements. Most of Japanese RDF are densified type, which are manufactured by adding calcium compounds and are classified as RDF-5 by ASTM standard. An RDF sample used in the experiments was a pellet type made from municipal solid waste. A pile (height: $15 \mathrm{~cm}$, base: $75 \mathrm{~cm} \mathrm{x} 75 \mathrm{~cm}$ ) of RDF was ignited and burned for predetermined burn time. By applying water mist, flame over the pile was extinguished. When burn time was $10 \mathrm{~min}$, the pile was cooled after extinguishing flame. Surface temperature observed by a thermal image camera dropped to the environmental temperature in less than 2 hours. When burn time was 30 min or $60 \mathrm{~min}$, hot area was found on the surface by a thermal image camera after extinguishing flame. Temperature at the hottest spot measured by a thermal image camera exceeded $250^{\circ} \mathrm{C}$. Hot area expanded with time. Smoke was emitted from the hot area. After the pile was cut open for inspection, hot area was found inside the pile. Temperature at $5 \mathrm{~cm}$ from the base was unchanged in spite of the expansion of hot area on the surface. Limitation of detection by thermocouple due to low thermal diffusivity was suggested. RDF pellets were aggregated by heating since shredded plastics contained in the pellets melted and worked as adhesive. By applying water, aggregated pellets were cooled to form a layer which prevents water from soaking inside. RDF pellets remained hot under the layer. If air was supplied to hot RDF pellets under the layer, oxidation continued and heat and smoke were emitted.

Spread rate of charred area beneath the surface was $0.1 \mathrm{~cm} / \mathrm{min}$. It was larger than the value predicted by an approximate analysis of heat transfer in the pile. It was suggested that oxygen was soaked into the charred area and heat was generated in the charred area due to oxidation.

\section{ACKNOWLEDGEMENTS}

The authors thank gratefully Yokohama City Fire Bureau for their help in performing the experiments.

\section{REFERENCES}

[1] Gupta, A.K., and Rohrbach, E.M., "Refuse Derived Fuels: Technology, Processing, Quality and Combustion Experiences,” Refuse-Derived Fuel (RDF) - Quality, Standards, and Processing, FACT-Vol. 13, ASME, 1991, pp. 49-59.

[2] J JIS TR Z 0011, Densified Refuse Derived Fuel, 2002.

[3] Japanese Fire and Disaster Management Agency, "Investigation Report on the Safety Management of Refuse Derived Fuel,” 2003, (in Japanese).

[4] Tsuruda, T., et al., "Explosions and Fires of an RDF-5 Silo," Proceedings of International Symposium on Industrial Safety 2004 (ISIS2004), 2004, pp. 31-35.

[5] Suzuki, T., “RDF Fires,” Anzen Kogaku, 43, pp. 254-261, 2004, (in Japanese). 
[6] Sato, K., "Property of RDF in Combustion," Nensho Kenkyu, 104, pp. 29-52, 1996, (in Japanese).

[7] Mori, S., "Property of RDF in Combustion," Nensho Kenkyu, 105, pp. 17-28, 1996, (in Japanese).

[8] Nakajima, K., "Property of RDF in Combustion,” Nensho Kenkyu, 106, pp. 2737, 1996, (in Japanese).

[9] Ikeda, H., "Property of RDF in Combustion,” Nensho Kenkyu, 107, pp. 23-29, 1997, (in Japanese).

[10] Gao, L., et al., "Possibility of Refuse Derived Fuel Fire Inception by Spontaneous Ignition," Proceedings of 6th Asia-Oceania Symposium on Fire Science and Technology, 2004, pp. 102-107.

[11] Gao, L., and Hirano, T., "Process of Accidental Explosions at a Refuse Derived Fuel Storage," Proceedings of the 5th International Symposium on Hazards, Prevention and Mitigation of Industrial Explosions, 2004.

[12] Yashima, M., "Fire Spread in Piled-up Layer of RDF (Refuse Derived Fuel)," Proceedings of 37th Symposium of Japan Society for Safety Engineering, pp. 189-192, 2004, (in Japanese).

[13] Yokkaichi City Fire Department, "Experiments on Burning and Extinguishment of RDF (Summary of the Report)," Gekkan Shobo 26, (May), pp. 26-31, 2004, (in Japanese).

[14] Golinveaux, J.E., and Hankins, J.E., "Sprinkler Systems for Storage Facilities,”, Fire Protection Handbook (19 ${ }^{\text {th }}$ ed.), Cote, A.E. (ed.), National Fire Protection Association, Quincy, MA 02269, 2003, pp. 10/215.

[15] Mie Prefecture, Documents distributed in Fourth Meeting on Safety Control of Mie RDF Power Station, 21 July 2004, (in Japanese).

[16] Yokohama City Fire Bureau, "Development of Pneumatic Atomizing Water Discharger for Firefighters Put Air Gas Cylinder to Use,” Bosai Kenkyu, 33, pp. 17-21, 2002, (in Japanese). 